\title{
Changes in Oleic Acid Content of Transgenic Soybeans by Antisense RNA Mediated Posttranscriptional Gene Silencing
}

\author{
Ling Zhang, Xiang-dong Yang, Yuan-yu Zhang, Jing Yang, Guang-xun Qi, Dong-quan Guo, \\ Guo-jie Xing, Yao Yao, Wen-jing Xu, Hai-yun Li, Qi-yun Li, and Ying-shan Dong
}

Agro-Biotechnology Research Institute, Jilin Academy of Agricultural Sciences, Changchun, Jilin 130033, China

Correspondence should be addressed to Qi-yun Li; qyli1225@126.com and Ying-shan Dong; ysdong@cjaas.com

Received 16 April 2014; Revised 10 July 2014; Accepted 21 July 2014; Published 13 August 2014

Academic Editor: Giuliana Napolitano

Copyright (c) 2014 Ling Zhang et al. This is an open access article distributed under the Creative Commons Attribution License, which permits unrestricted use, distribution, and reproduction in any medium, provided the original work is properly cited.

\begin{abstract}
The Delta-12 oleate desaturase gene (FAD2-1), which converts oleic acid into linoleic acid, is the key enzyme determining the fatty acid composition of seed oil. In this study, we inhibited the expression of endogenous Delta-12 oleate desaturase GmFad2-1b gene by using antisense RNA in soybean Williams 82. By employing the soybean cotyledonary-node method, a part of the cDNA of soybean $G m F a d 2-1 b 801$ bp was cloned for the construction of a pCAMBIA3300 vector under the soybean seed promoter BCSP. Leaf painting, LibertyLink strip, PCR, Southern blot, qRT-PCR, and fatty acid analysis were used to detect the insertion and expression of GmFad2-1b in the transgenic soybean lines. The results indicate that the metabolically engineered plants exhibited a significant increase in oleic acid (up to 51.71\%) and a reduction in palmitic acid (to $<3 \%$ ) in their seed oil content. No structural differences were observed between the fatty acids of the transgenic and the nontransgenic oil extracts.
\end{abstract}

\section{Introduction}

Vegetable oils form an important part of the human diet, providing concentrated sources of energy and essential nutrients. A process is used for the deacidification of a vegetable oil in which the major acid of the vegetable oil is from the group comprised of epoxy fatty acids, hydroxy fatty acids, linoleic acid, and oleic acid [1]. The consumption of oils with high oleic acid content is beneficial because this monounsaturated fatty acid not only improves the shelf life but also reduces the need for hydrogenation, a process adding to the cost of the oil as well as generating unwanted trans fat that has been linked to many health problems in humans [2-4]. The commodity soybean oil is composed of five fatty acids: oleic acid (18:1), palmitic acid (16:0), stearic acid (18:0), linoleic acid (18:2), and linolenic acid (18:3). The percentages of these five fatty acids in soybean oil average are $18 \%, 10 \%, 4 \%, 55 \%$, and $13 \%$, respectively [5]. Most polyunsaturated fatty acids, up to $90 \%$ in nonphotosynthetic tissues of plants, are synthesized through a (18:1) desaturase in the endoplasmic reticulum. The endoplasmic reticulum-associated oleate desaturase FAD2 (1acyl-2-oleoyl-sn-glycero-3-phosphocholine $\Delta$ 12-desaturase) is the key enzyme responsible for the production of linoleic acid in plants [6-8].

In soybeans, two copies of microsomal $\omega-6$ desaturase, FAD2-1 and FAD2-2, have been cloned [9]. Studies have shown that FAD2-1 was expressed primarily in the development of seeds, while FAD2-2 was expressed in both the vegetative tissues and the development of seeds [10, 11]. Also, the FAD2-2 desaturases consisted of FAD2-2A (Glyma19g32930), FAD2-2B (Glyma19g32940), and FAD2-2C (Glyma03g30070). FAD2-1A and FAD2-1B are most closely related to one another, with a shared genomic organization containing a single intron and a $99 \%$ identity in encoded amino acid sequence. Thereby, this confirmed the importance expression during peak oil synthesis, while a possible role was also revealed for FAD2-2C under cool temperature conditions [12-14]. Genetic modification (GM) aimed at regulating the FAD2 expression has been applied to produce oils with a higher C18:1 in soybeans [15-19]. For example, by antisense suppression of FAD2 in soybeans, a transgenic line was obtained that produced oil with a higher C18:1 (57\%) compared to the wild variety [20]. Similarly, downregulating FAD2-1 and FatB using interference RNA has enabled the 
TABLE 1: Primers for different experiments.

\begin{tabular}{lll}
\hline Primer name & Primer sequence & PCR producer $(\mathrm{bp})$ \\
\hline GmFAD2-1b-F & $5^{\prime}$-AGCCACTAGGCATGGGTCTAGCAAA-3 & 801 \\
GmFAD2-1b-R & $5^{\prime}$-GCAATGGCACCCCATAAACACATAG-3 & 752 \\
EB-R & $5^{\prime}$-GGAAAGCAACCATATCAGCATATCAC-3' \\
EB-F & $5^{\prime}$-TTCTCCAAGGTTGCATTCTTACTGG-3' \\
GmActin-R & $5^{\prime}$-TTGACTGAGCGTGGTTATTCC-3' \\
GmActin-F & $5^{\prime}$-GATCTTCATGCTGCTGGGTG-3' \\
qRTGmFad2-R & $5^{\prime}$-CACCATTCACTGTTGGCCAA-3' \\
qRTGmFad2-F & $5^{\prime}$-ATGAGGGAAAAGGGGTGAGG-3' & 402 \\
\hline
\end{tabular}

production of soybeans with a significantly higher oleic acid content (up to $94.58 \%$ ) and reduced levels of palmitic acid $(<3 \%)$ [21]. Recently, Plenish high oleic soybeans have been in commercial production by DuPont since 2012. They were developed using a biotech process known as gene silencing [22]. These results demonstrate that the GmFAD2 family members play a very important role in metabolically engineered oil seed plants [23].

In this study, we report the transformation of soybean with GmFad2-1b gene by antisense RNA. We analyzed and investigated the fatty acid composition of the transgenic lines and also discussed the nature of the transcript produced by GmFad2-1b.

\section{Materials and Methods}

2.1. Plant Materials and Cotyledonary-Node Method. Soybean cultivars [Glycine max (L.) Merrill cv. "Williams 82"] were grown in a greenhouse at the Jilin Academy of Agricultural Sciences, Gongzhuling, during a $16 \mathrm{~h}$ photoperiod at a $35^{\circ} \mathrm{C}$ daytime temperature and a $25^{\circ} \mathrm{C}$ night-time temperature. The cotyledonary-node method used in this study followed the procedure described by Paz et al. [24]. In brief, soybean seeds were surface-sterilized by placing seeds into a tightly sealed chamber containing chlorine gas for $16 \mathrm{~h}$. The sterilized seeds were soaked with sterile water at $28^{\circ} \mathrm{C}$ during an $18 \mathrm{~h}$ photoperiod for $8-12 \mathrm{~h}$. The imbibed soybean seeds were placed on sterile filter paper and cut longitudinally along the hilum. The cotyledons and hypocotyls $(\sim 5 \mathrm{~mm})$ from a single seed were split evenly into two explants. Approximately 50 coat-removed explants were then inoculated in a liquid cocultivation medium (CCM), which contains 1/10 B5 salts and vitamins, $3.9 \mathrm{~g} / \mathrm{L}$ 2-[N-morpholino] ethanesulfonic acid (MES), $3 \%$ sucrose $(30 \mathrm{~g} / \mathrm{L})(\mathrm{pH} 4)$, filter-sterilized $0.25 \mathrm{mg} / \mathrm{L}$ gibberellic acid (GA3), $400 \mathrm{mg} / \mathrm{L}$ L-cysteine, $1.67 \mathrm{mg} / \mathrm{L} \mathrm{N}-6$ benzylaminopurine (BAP), $154.2 \mathrm{mg} / \mathrm{L}$ dithiothreitol (DTT), and $200 \mu \mathrm{mol} / \mathrm{L}$ acetosyringone (As) for $30 \mathrm{~min}$. After this inoculation, seven explants (adaxial side up) were randomly placed in Petri dishes ( $90 \mathrm{~mm}$ in diameter $\times 15 \mathrm{~mm}$ deep) on sterile filter paper, placed on solid CCM containing $0.5 \%$ purified agar (BD-Difco), and incubated in the dark at $25^{\circ} \mathrm{C}$ for 3-5 days.

After the cocultivation, the explants were then transferred into solidified shoot induction (SI) medium containing B5 salts and vitamins, $3 \%$ sucrose, $0.8 \%$ agar ( $8 \mathrm{~g} / \mathrm{L}$; Sigma),
$0.58 \mathrm{mg} / \mathrm{L}$ MES (pH 5.8), filter-sterilized $1.67 \mathrm{mg} / \mathrm{L}$ BAP, $250 \mathrm{mg} / \mathrm{L}$ ticarcillin (Tic), $100 \mathrm{mg} / \mathrm{L}$ cefotaxime (Cef), and $5 \mathrm{mg} / \mathrm{L}$ glufosinate and then incubated in a growth room at $28^{\circ} \mathrm{C}$ under an $18 \mathrm{~h}$ photoperiod for two weeks. Then, the hypocotyl and shoots were trimmed from the explants and the remaining cotyledons with developing nodules were subcultured to a fresh SI medium for another two weeks. Four weeks after SI, the cotyledons were removed from the explants and the remaining tissues were transferred into a shoot elongation (SE) medium. The SE medium was composed of MS salts and vitamins, $3 \%$ sucrose, $0.8 \%$ agar (Sigma), $0.58 \mathrm{mg} / \mathrm{L}$ MES, filter-sterilized $50 \mathrm{mg} / \mathrm{L}$ L-asparagine, $50 \mathrm{mg} / \mathrm{L}$ glutamine, $0.1 \mathrm{mg} / \mathrm{L}$ indole acetic acid (IAA), $0.5 \mathrm{mg} / \mathrm{L}$ GA3, $1 \mathrm{mg} / \mathrm{L}$ zeatin riboside (ZR), $250 \mathrm{mg} / \mathrm{L} \mathrm{Tic,} 100 \mathrm{mg} / \mathrm{L} \mathrm{Cef,} \mathrm{and}$ $5 \mathrm{mg} / \mathrm{L}$ glufosinate ( $\mathrm{pH}$ 5.8). The explants were then transferred to fresh SE medium every two weeks until the regenerated shoots were suitable for rooting. The incubation conditions were the same as the conditions for SI. At this point, elongated shoots (3-4 cm in length) were excised and placed into a rooting medium (RM) containing $\mathrm{MS}$ salts and vitamins, $3 \%$ sucrose, $0.8 \%$ agar (Sigma), $0.58 \mathrm{mg} / \mathrm{L}$ MES (pH 5.8), filter-sterilized $50 \mathrm{mg} / \mathrm{L} \mathrm{L}$-asparagine, $50 \mathrm{mg} / \mathrm{L}$ glutamine, $0.1 \mathrm{mg} / \mathrm{L}$ indole butyric acid (IBA), $250 \mathrm{mg} / \mathrm{L} \mathrm{Tic}$, and $100 \mathrm{mg} / \mathrm{L}$ Cef. After a period of 1-2 weeks, the roots were fully developed to $2-3 \mathrm{~cm}$ in length and eventually transplanted into the pots to be grown in the greenhouse. The transgene events were named by EB8001 to EB8067. The T0 generation transgenic plants were grown in the greenhouse and the $T_{1}$ and $\mathrm{T}_{2}$ lines were grown under field conditions.

2.2. Nucleic Acid Isolation and Vector Construction. The fresh soybean tissues were collected to extract the total RNA with TRIZOL reagent (Invitrogen). RNA samples $(2 \mu \mathrm{g})$ were treated with the amplification grade DNase I (Invitrogen) at $37^{\circ} \mathrm{C}$ for $15 \mathrm{~min}$ prior to cDNA synthesis using SuperScript III Reverse Transcriptase (Invitrogen) according to the manufacturer's instructions.

For the assembly of the GmFad2-1b antisense RNA vector, a part of a fragment about 801 bp of the GmFad2-1b (GenBank accession: XM_003555831) was amplified from the cDNA above by using the primers GmFad2-1b-F/GmFad2$1 \mathrm{~b}-\mathrm{R}$ (Table 1). The amplified GmFad2-1b gene product was cloned into the pEASY-T1 cloning vector (TransGene). The product was sequenced using T7 and M13 vector sequencing primers to confirm the sequence of the ligated product. An 
801 bp XbaI/SacI T1-vector digested GmFad2-1b fragment was anticloned into a pCAMBIA3300 vector and digested with the same enzymes to put the $G m F a d 2-1 b$ gene under the seed $\alpha^{\prime}$ subunit of the $\beta$-conglycinin promoter (BCSP) with the different direction, and the $B C S P^{\prime}$ function was discussed by Imoto et al. [25]. The pCAMBIA3300 binary vector has a kanamycin resistance gene for bacterial selection and a phosphinothricin acetyl transferase (bar) resistance gene for plant selection. The bar gene was driven by the constitutive CaMV 35S promoter. The Agrobacterium tumefaciens strain EHA101 was used in this study.

2.3. Detection of Transgenic Soybean Plants. Transgenic soybean plants were verified by leaf painting, LibertyLink strip analysis, polymerase chain reaction (PCR) analysis, and Southern blot. Leaf painting was performed following the procedure described by Ma et al. [26]. Stock of LibertyLink Basta (135 g/L) was diluted by 1000 -fold and painted on half the upper surface of the tested soybean leaves. After 3-5 days, the painted leaves of the negative plants died and positive plants remained healthy. LibertyLink strips (Envirologix) were used to determine the genetically modified plants containing the phosphinothricin $\mathrm{N}$-acetyltransferase (PAT) protein following the manufacturer's instructions. To summarize, a circular leaf tissue was isolated by closing the cap of the Eppendorf tubes. The tissue was ground with a pestle for 20$30 \mathrm{sec}$ and $0.25 \mathrm{~mL}$ of protein extraction buffer was added before regrinding. The development of the control line indicated that the strip had functioned properly. The second line (test line) would show up when the tested sample was positive.

For the PCR analysis, the genomic DNA of transgenic soybeans was extracted using a simple and quick DNA extracting method by Edwards et al. [27]. We designed the detection primers named EB-R/F according to the GmFad2$1 b$ gene and the upstream BCSP promoter sequence. The length of the product was $752 \mathrm{bp}$. The primer sequence can be seen in Table 1 . The PCR reaction was conducted using an initial denaturation at $94^{\circ} \mathrm{C}$ for $5 \mathrm{~min}$, followed by 30 cycles of $94^{\circ} \mathrm{C}$ for $45 \mathrm{sec}, 58^{\circ} \mathrm{C}$ for $45 \mathrm{sec}$, and $72^{\circ} \mathrm{C}$ for $1 \mathrm{~min}$ and a final extension of $10 \mathrm{~min}$ at $72^{\circ} \mathrm{C}$. The PCR products were analyzed on $1.0 \%$ agarose gels. As a positive control, a $\mathrm{GmFad2}-1 \mathrm{~b}$ gene expression cassette containing pCAMBIA3300 vector DNA was also used. The genomic DNA from the empty pCAMBIA3300 vector transformed plant and the untransformed Williams 82 were used as negative controls.

A Southern blot analysis of the PCR positive plants was performed by DIG High Prime DNA Labeling and Detection Starter Kit II (Roche, cat. number 11585614910) according to the manufacturer's instructions. The genomic DNA of transgenic $\mathrm{T}_{1}$ and $\mathrm{T}_{2}$ plants was isolated by using the highsalt CTAB DNA method. In summation, $20 \mu \mathrm{g}$ of genomic DNA was digested with $\mathrm{XbaI}$ and HindIII electrophoresed on $1.0 \%$ agarose gel, respectively. The DNA was denatured by an alkaline solution and transferred to positively charged Amersham nylon membranes (Amersham) according to standard protocol and fixed by UV-crosslinking at $1200 \mathrm{U}$ for $1 \mathrm{~min}$. Since the GmFad2-1b gene and seed-specific promoter BCSP were endogenous genes, we took the marker gene bar in pCAMBIA3300 vector as the probe for the Southern blot. The probe was labeled using digoxigenin- (DIG-) 11-dUTP with DIG High Prime DNA Labeling Reagents (Roche). Hybridization was carried out at $42^{\circ} \mathrm{C}$. Washing, blocking, and detection were carried out according to the manufacturer's instructions. The Southern blots were then exposed at room temperature for 15-20 min and subsequently developed.

2.4. Fatty Acid Analysis. The fatty acid compositions of the seeds harvested from $\mathrm{T}_{1}$ and $\mathrm{T}_{2}$ transgenic plants were analyzed by gas chromatography (GC). First, the lyophilized soybean seeds were ground to a fine powder, and then the lipids were extracted with heptane. The supernatant was then transferred into a glass vial, and the heptane was evaporated with a flow of dry nitrogen gas at $80^{\circ} \mathrm{C}$. At this point, an $8 \mathrm{mg}$ aliquot of the extracted soybean oil was transesterified with sodium methoxide. The fatty acid methyl esters were then separated on a Hewlett-Packard 6890 GC supplied with a hydrogen flame ionization detector and a capillary column HP INNOWAX (30 m; $0.25 \mathrm{~mm}$ i.d.) with an N2 carrier at $2 \mathrm{~mL} / \mathrm{min}$. The oven temperature was maintained at $100^{\circ} \mathrm{C}$ for a minimum of $1 \mathrm{~min}$ and then increased linearly to $250^{\circ} \mathrm{C}$ $\left(15^{\circ} \mathrm{C} / \mathrm{min}\right)$. The fatty acid methyl esters (FAMEs) from TAG were identified by comparison of their retention times with the known standards (37-component FAME mix, Supelco 47885-U). Relative fatty acid compositions were then calculated as the percentage that each fatty acid represented of the total measured fatty acids.

2.5. Quantitative RT-PCR Analysis. The total RNA was extracted by using a TRIZOL reagent kit (Invitrogen) from the different issues of the mature $\mathrm{T}_{2}$ transgenic plants and wild types. At this point, two $\mu$ g total RNA from each sample was reverse-transcribed by using the PrimeScript RT reagent kit (Takara) with an oligo (dT) 18 primer. Quantitative PCR was performed on the real-time PCR system (Applied Biosystems, 7900) with SYBR Premix Ex Taq (Takara), with the conditions of $95^{\circ} \mathrm{C}$ for $30 \mathrm{sec}$, followed by 40 cycles of $95^{\circ} \mathrm{C}$ for $5 \mathrm{sec}$ and $60^{\circ} \mathrm{C}$ for $30 \mathrm{sec}$. The GmActin gene (NM_001289231) was used as a positive internal control and the gene primers for the qRT-PCR were designed using conserved sequences for them as listed in Table 1.

\section{Results and Discussion}

The high-frequency plant gene transfer system is one of the key stages for introducing useful or novel gene(s) into soybeans. In this study, we used the cotyledonary explant derived from mature soybean seeds for Agrobacterium-mediated transformation. The entire procedure for the Agrobacteriummediated cotyledonary-node transformation system used in this study is illustrated in Figure 1 and Table 2. Additionally, high-level expression of recombinant molecules has been consistently achieved by utilizing specific regulatory sequences within the seed tissues. The cobombardment transformation strategy to generate transgenic soybean 
TABLE 2: Transformation efficiency of soybean cotyledonary-node explants inoculated with Agrobacterium tumefaciens's strain EHA101 harboring EB gene (pCamibia3300-BCSP-anti-GmFad2).

\begin{tabular}{lccccc}
\hline $\begin{array}{l}\text { Number of } \\
\text { experiments }\end{array}$ & Genotype & Explants infected & $\begin{array}{c}\text { Plants surviving } \\
\text { on SE medium }\end{array}$ & $\begin{array}{c}\text { Positive } \mathrm{T}_{0} \\
\text { transformation }\end{array}$ & $\begin{array}{c}\text { Transformation } \\
\text { efficiency }(\%)\end{array}$ \\
\hline 1 & Williams 82 & 96 & 24 & 16 & 16.73 \\
2 & Williams 82 & 114 & 36 & 18 & 15.84 \\
3 & Williams 82 & 117 & 45 & 17 & 55 \\
\hline
\end{tabular}

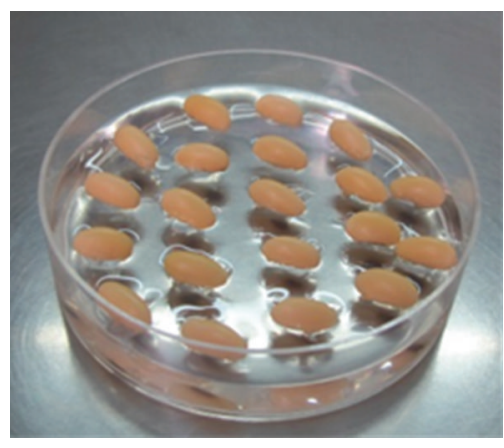

(a)

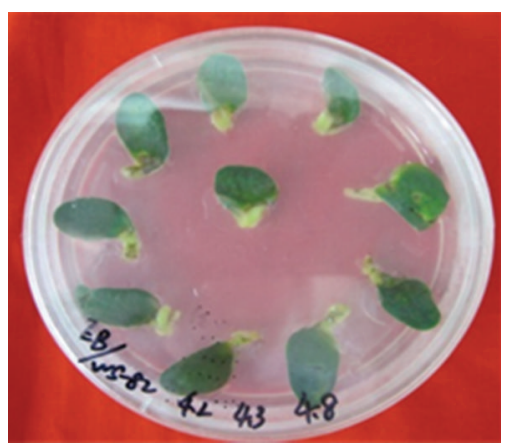

(d)

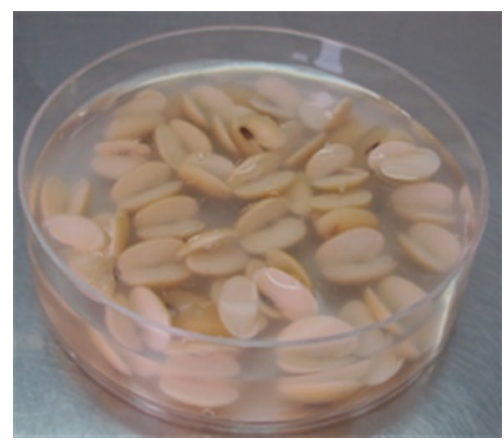

(b)

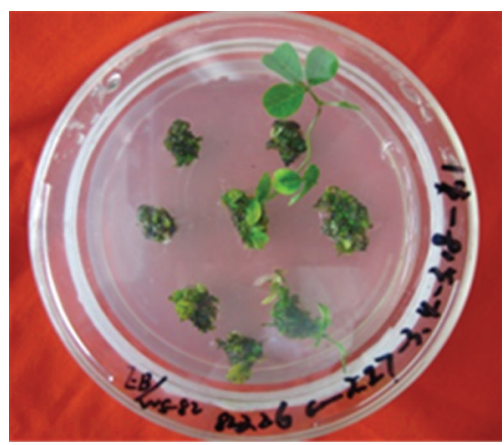

(e)

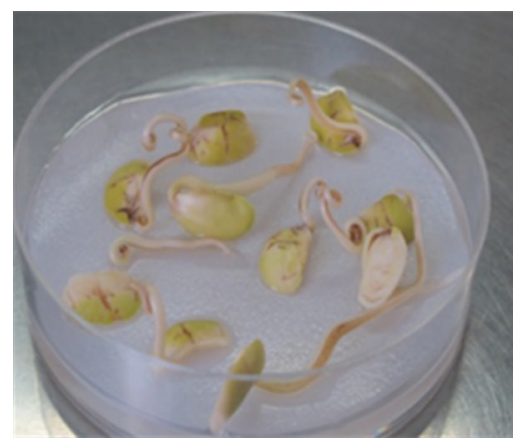

(c)

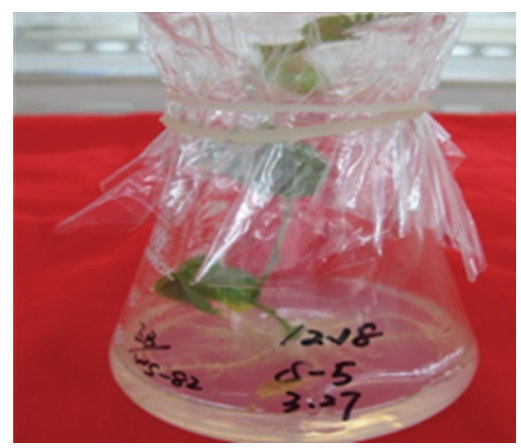

(f)

FIGURE 1: Agrobacterium-mediated soybean transformation using the cotyledonary node as explants. (a) Seed germination in the GM medium for the night. (b) Inoculation of explants with Agrobacterium. (c) A longitudinal cut between the cotyledons and through the hypocotyl to generate two identical explants. (c) Explants cocultured with Agrobacterium for 5 days. (d) Two weeks after selection on shoot induction (SI) medium containing $5 \mathrm{mg} / \mathrm{L}$ glufosinate. (e) Elongated shoot in shoot elongation (SE) medium. (f) Rooting of the resistant shoot.

plants allowed us to evaluate the pCAMBIA3300-BCSP-antiGmFad2-1b plasmid vector (Figure 2). The gene encoding of the anti-GmFad2-1b was placed under the control of $\alpha^{\prime}$ subunit of the $\beta$-conglycinin (BCSP) soybean promoter and was introduced into the soybean genome with the aim of high-level suppressions, which resulted in a high oleic acid content in the soybean seeds. The promoter BCSP is tissuespecific and temporally regulated and is not expressed in the roots, stems, or leaves of soybean. In this study, the gene $G m F a d 2-1 b$ under promoter BCSP was not expressed in the seed of soybean as expected from the result of the qRTPCR assay (Figure 5). Regulatory information for the tissuespecific expression mediated by the BCSP promoter and the other elements involved in the modulation of the expression of genes associated with seed storage protein has been localized to the DNA sequences approximately $250 \mathrm{bp}$ upstream from the transcription start site $[28,29]$.
For the detection of the transgenic soybean plants, we used three methods (the leaf painting, the LibertyLink strip analysis, and the PCR) to confirm the positive transgene plants. We performed 200 Williams 82 on the seeds, which contains about 327 explants infected by the cotyledonarynode method. Finally, we obtained $105 \mathrm{~T}_{0}$ transgenic regeneration plants and a total of 55 plants tested positive, giving a $5.5 \%$ transformation efficiency. Figure 3 shows a part of detection results by leaf painting, LibertyLink strip, and PCR analysis. Although the $\mathrm{T}_{0}$ transgenic plants were generated in the lab, while the $T_{1}, T_{2}$ were generated in the field, the rapid and exact method for determining positive transgenic status was pivotal. The PCR detection of a selected marker gene is a traditional and effective way of doing this, although false positive results are sometimes observed. Therefore, we checked a part of the sequence between the BCSP and the anti-GmFad2-1b at about $752 \mathrm{bp}$ in the vector for the 

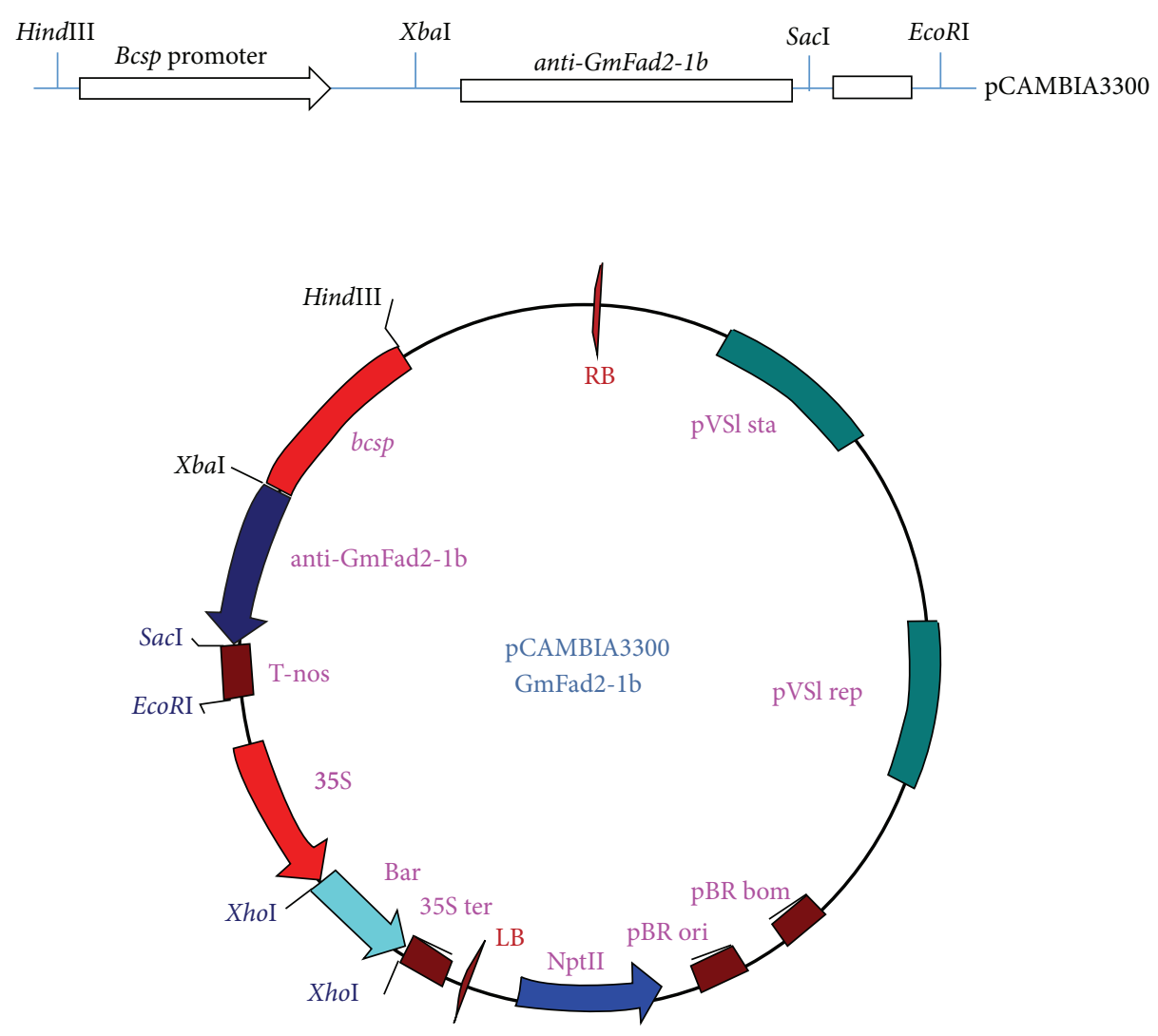

Figure 2: Map of vector pCmbia3300-Bcsp-GmFad2. A schematic representation of the expression cassettes of the anti-GmFad2-1b and pCAMBIA3300 plasmids used for Agrobacterium-mediated transformation of soybean cotyledonary node. The anti-GmFad2-1b gene is under the control of the soybean seed promoter and 30 region (terminator).

identification of any transgenic plants (Figure 3(c)). However, the primary PCR testing is cumbersome and costly. Instead of the PCR procedures, a leaf painting method was chosen. As leaf painting directly detected the effect of a selected marker gene, it showed fewer false positive results than the PCR procedures. Furthermore, the leaf painting method was low in cost and easy to carry out (Figure 3(a)). Since the GmFad2$1 b$ gene fragment did not code for a functional protein, no novel protein was produced from the GmFad2-1b gene cassette. However, the expressing cassette contains the bar marker gene, which is characterized by a resistance to the herbicide bialaphos. The LibertyLink strips could therefore be used to quickly determinate genetically modified plants containing the bar gene (Figure 3(b)). By the methods stated above, we identified 55 positive $\mathrm{T}_{0}$ transgenic plants from the total $105 \mathrm{~T}_{0}$ transgenic lines. We also used these detection methods to examine the $T_{1}$ and $T_{2}$ progenies of every independently transformed $\mathrm{T}_{0}$ line. 11 of the 55 positive $\mathrm{T}_{0}$ lines were further regenerated to $T_{1}$ lines and then $T_{2}$ lines. All 11 plants which exhibited Basta resistance also showed amplification of the bar gene in the PCR analysis (results not shown), thereby confirming the presence and expression of the transgene in transgenic the soybean plants.

Consequently, because the GmFad2-1b gene and seedspecific promoter $B C S P$ were endogenous genes, the marker gene bar in the pCAMBIA3300 vector became the probe for the Southern blot among the $11 \mathrm{~T}_{2}$ transgene lines. In addition, in order to guarantee the accuracy of the Southern blot, we used two different restriction enzymes, $\mathrm{XbaI}$ and HindIII, for digesting genomic DNA. Based on the Southern blot analysis and sequence data, it was determined that the bar gene cassette and the GmFad2-1b gene cassette have been inserted into the soybean genome (Figure 4). In previous studies there have been suggestions that if a high transgene copy number were integrated into the $\mathrm{T}_{0}$ plants, the alternative DNA copies should be integrated at different loci with a low recombination frequency [30]. This result was corroborated in our study by the Southern blot analyses of different $T_{2}$ plants lines, EB8003, EB8005, EB8006, and EB8065, which presented at least four bar copies. One concern related to these high transgene copy numbers that were integrated in the host genome is the possibility of superfluous tandem integration, which could result in possible gene silencing and low recombinant protein production levels [29]. The lines EB8019, EB8011, EB8057, and EB8067 showed one or two copies, and the lines EB8007 and EB8008 cannot be confirmed by the two restriction enzymes at same time. All of the transgenic plants regenerated grew normally and set flowers and pods.

Increasing the oleic acid content in soybean seed oil is one of the most effective and efficient ways to enhance the nutritional value and practical utilization of soybean oil. 


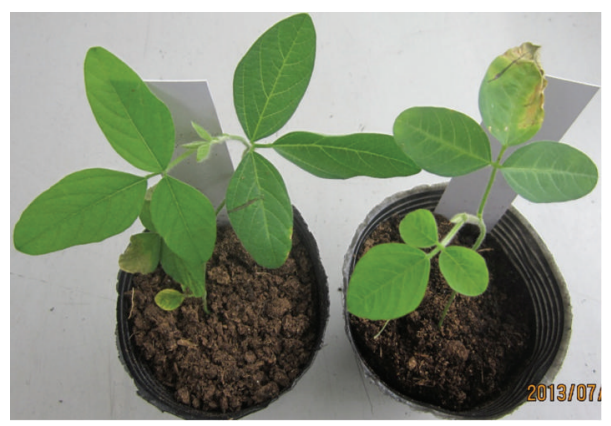

(a)

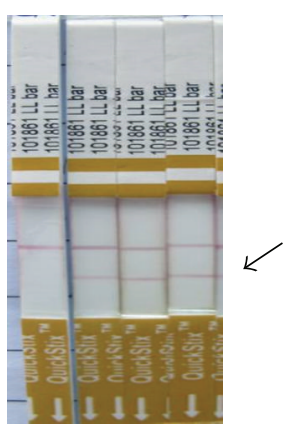

(b)

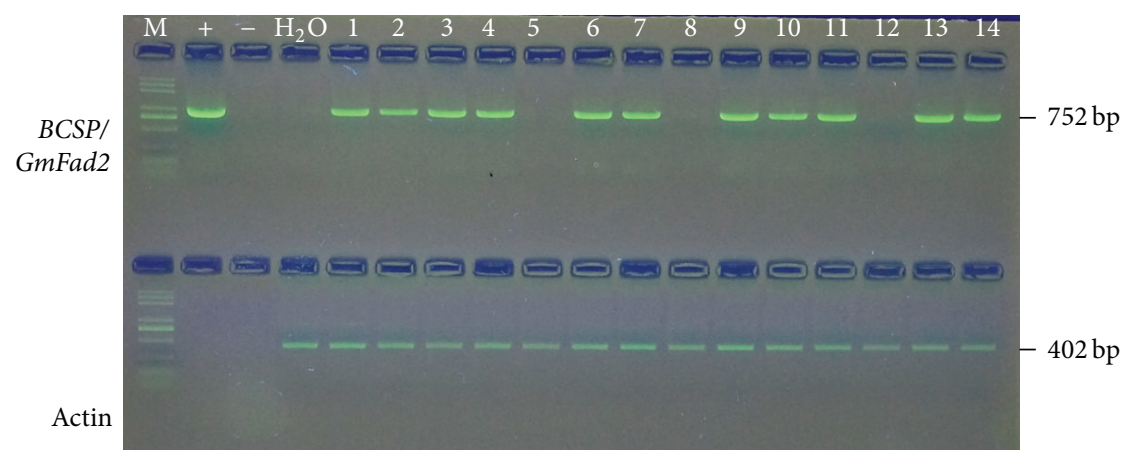

(c)

FIgURE 3: Procedure for confirmation of transgenic plants. (a) Identification of the herbicide resistance of the leaves of transgenic soybean plants using $135 \mathrm{mg} / \mathrm{L}$ Basta. Left: negative transgenic plant; right: positive transgenic plants. (b) Events of the PCR positive lines were randomly selected and tested using LibertyLink strips. (c) PCR analysis of genome DNA of putative transgenic soybean plant. The length of PCR production was 752 bp. M: trans2K plus DNA marker; +: plasmid DNA; -: nontransformed soybean; $\mathrm{H}_{2} \mathrm{O}$. 1-14: the transgene line.
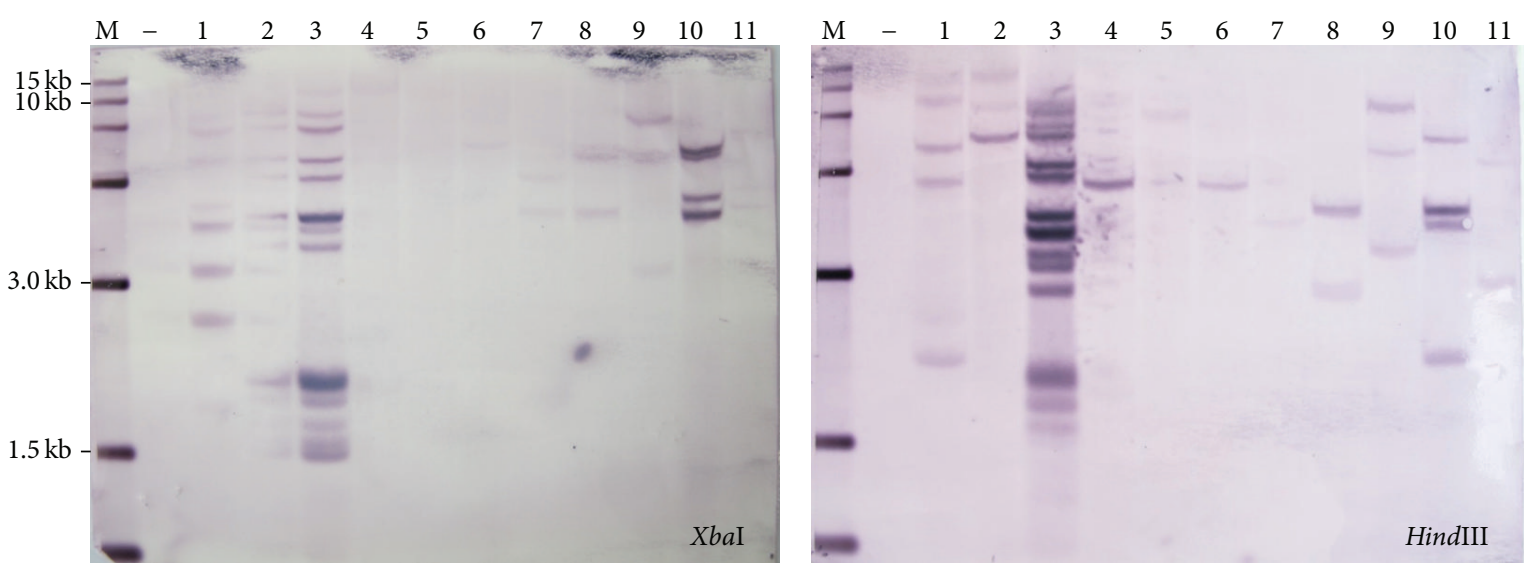

FIGURE 4: Southern blot hybridization of transgenic plants. The soybean genomic DNA was sampled from 11 independent events in the $\mathrm{T}_{2}$ generation (1-11) and digested with two different restriction enzymes, XbaI and HindIII, and hybridized with the bar probe labeled with DIG.

The overall lipid content of $11 \mathrm{~T}_{2}$ transgenic lines of soybean grain remained unchanged compared to the conventional soybean grain. Using fatty acid analysis, we selected three high oleic acid modified materials in the $\mathrm{T}_{2}$ transgene lines. They are EB8011, EB8057, and EB8061. The EB8011 soybean grain contains increased levels of oleic acid (up to $51.71 \%)$ and lower levels of linoleic acid (27.32\%), linolenic acid (8.47\%), and to a lesser extent palmitic acid (8.72\%). In addition, EB8057 oleic acid content is $38.23 \%$, and EB8061 oleic acid content is $40.48 \%$, which were significantly higher than the receptor controls (17.70\%) (Table 3). The lines EB8011 and EB8057 were presented at two copies in soybean genomic DNA while the line EB8061 was presented at three. In previous studies, FAD2 genes were identified as encoding $\omega-6$ fatty acid desaturases which catalyze the conversion of 18:1 oleic acid to $18: 2$ linoleic acid in soybeans $[6,11]$. This conversion is of particular interest in the soybeans due to the growing desire for low linoleic soybean oil [4]. Moreover, a 
TABLE 3: GC-MS results yielding the oil composition of the transgenic soybean seed line.

\begin{tabular}{|c|c|c|c|c|c|c|}
\hline Sample & Generation & $\%$ palmitic & $\%$ stearic & $\%$ oleic & $\%$ linoleic & $\%$ linolenic \\
\hline $\mathrm{CK}$ & Williams 82 & 10.49 & 4.47 & $17.70 \pm 0.20$ & 57.84 & 8.50 \\
\hline 1 & EB8003 & 10.63 & 3.58 & $14.96 \pm 0.01$ & 62.44 & 8.38 \\
\hline 2 & EB8005 & 10.50 & 4.02 & $16.22 \pm 0.12$ & 59.85 & 9.41 \\
\hline 3 & EB8006 & 10.59 & 4.20 & $16.85 \pm 0.04$ & 58.82 & 9.53 \\
\hline 4 & EB8007 & 10.33 & 3.95 & $17.07 \pm 0.12$ & 59.23 & 9.42 \\
\hline 5 & EB8008 & 10.53 & 3.80 & $15.39 \pm 0.05$ & 60.19 & 10.10 \\
\hline 6 & EB8019 & 11.13 & 4.10 & $16.55 \pm 1.14$ & 58.25 & 9.96 \\
\hline 7 & EB8011 & 8.72 & 2.93 & $51.17 \pm 0.25^{* *}$ & 27.32 & 8.47 \\
\hline 8 & EB8057 & 9.80 & 3.51 & $38.23 \pm 0.05^{* *}$ & 38.35 & 10.11 \\
\hline 9 & EB8061 & 9.19 & 3.76 & $40.48 \pm 0.08^{* *}$ & 37.44 & 9.12 \\
\hline 10 & EB8065 & 10.55 & 3.96 & $14.25 \pm 0.09$ & 60.63 & 10.61 \\
\hline 11 & EB8067 & 10.20 & 3.67 & $21.93 \pm 0.05$ & 54.03 & 10.17 \\
\hline
\end{tabular}

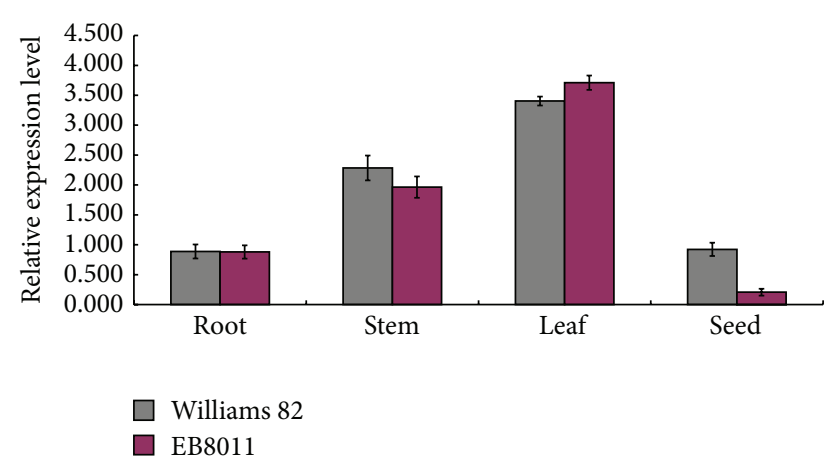

FIGURE 5: qRT-PCR analysis of GmFad2-1b in the different tissue. RNA was extracted from root, steam, leaf, and early flowering seed. The abundance of GmFad2-1b transcripts was normalized to that of Actin transcripts.

high oleic acid content is desirable because this monounsaturated fatty acid not only improves shelf life but also reduces the need for hydrogenation, a process which adds to the cost of the oil and generates unwanted trans fat that has been linked to many health problems in humans [1]. Our study demonstrated high-level suppression of $G m F a d 2-1 b$ by antiRNA while also resulting in a high oleic acid in the soybeans.

\section{Conclusions}

We were successful in the suppression expression GmFad2-1b in transgenic soybean seeds. Based on the published results on soybeans, the soybean GmFAD2 gene family has been previously characterized at the genome level for structure and expression [9-11] and also in genetic modification [15-19]. In our study, silencing of the endogenous Fad2-1 gene in seeds of the soybean event EB8011 was achieved through the introduction of a $G m F a d 2-1 b$ gene fragment driven by a seed-specific promoter. The transcription of the GmFad2-1b gene fragment in the seed acts to silence transcription of the endogenous FAD2-1 gene. The line EB8011 had a result of $51.17 \%$ oleic acid and $8.72 \%$ palmitic acid, in contrast to $17.7 \%$ oleic acid and $4.47 \%$ palmitic acid in the seeds. In future studies, we also expect that the altered ratio of oleic and linoleic acid will confer desirable properties on the resulting biodiesel, without a significant change in the yield.

\section{Conflict of Interests}

The authors declare that there is no conflict of interests regarding the publication of this paper.

\section{Authors' Contribution}

Ling Zhang and Xiang-dong Yang contributed to this work equally.

\section{Acknowledgments}

This work is supported by a Project from the Ministry of Agriculture of China for Transgenic Research (Grants 2013ZX08004-003, 2011ZX08004-003, 2008ZX08004-003, and 2013ZX08004-004). The authors alone are responsible for the content and composition of this paper.

\section{References}

[1] K. L. Fritsche, "Linoleic acid, vegetable oils \& inflammation," Missouri Medicine, vol. 111, no. 1, pp. 41-43, 2014.

[2] S. Bhardwaj, S. J. Passi, and A. Misra, "Overview of trans fatty acids: biochemistry and health effects," Diabetes and Metabolic Syndrome, vol. 5, no. 3, pp. 161-164, 2011.

[3] H. Sales-Campos, P. R. de Souza, B. C. Peghini, J. S. da Silva, and C. R. Cardoso, "An overview of the modulatory effects of oleic acid in health and disease," Mini-Reviews in Medicinal Chemistry, vol. 13, no. 2, pp. 201-210, 2013.

[4] A. R. Raneses, L. K. Glaser, J. M. Price, and J. A. Duffield, "Potential biodiesel markets and their economic effects on the agricultural sector of the United States," Industrial Crops and Products, vol. 9, no. 2, pp. 151-162, 1999.

[5] T. E. Clemente and E. B. Cahoon, "Soybean oil: genetic approaches for modification of functionality and total content," Plant Physiology, vol. 151, no. 3, pp. 1030-1040, 2009. 
[6] J. Okuley, J. Lightner, K. Feldmann, N. Yadav, E. Lark, and J. Browse, "Arabidopsis FAD2 gene encodes the enzyme that is essential for polyunsaturated lipid synthesis," Plant Cell, vol. 6, no. 1, pp. 147-158, 1994.

[7] J. P. Spychalla, A. J. Kinney, and J. Browse, "Identification of an animal $\omega-8$ fatty acid desaturase by heterologous expression in Arabidopsis," Proceedings of the National Academy of Sciences of the United States of America, vol. 94, no. 4, pp. 1142-1147, 1997.

[8] S. Cao, X. Zhou, C. C. Wood et al., "A large and functionally diverse family of Fad2 genes in safflower (Carthamus tinctorius L.)," BMC Plant Biology, vol. 13, no. 1, article 5, 2013.

[9] J. A. Schlueter, I. F. Vasylenko-Sanders, S. Deshpande et al., “The FAD2 gene family of soybean: insights into the structural and functional divergence of a paleopolyploid genome," Crop Science, vol. 47, no. 1, pp. 14-26, 2007.

[10] M. F. Miquel and J. A. Browse, "High-oleate oilseeds fail to develop at low temperature," Plant Physiology, vol. 106, no. 2, pp. 421-427, 1994.

[11] E. P. Heppard, A. J. Kinney, K. L. Stecca, and G. H. Miao, "Developmental and growth temperature regulation of two different microsomal $\omega-6$ desaturase genes in soybeans," Plant Physiology, vol. 110, no. 1, pp. 311-319, 1996.

[12] G. Tang, W. P. Novitzky, H. Carol Griffin, S. C. Huber, and R. E. Dewey, "Oleate desaturase enzymes of soybean: evidence of regulation through differential stability and phosphorylation," Plant Journal, vol. 44, no. 3, pp. 433-446, 2005.

[13] E. P. Heppard, A. J. Kinney, K. L. Stecca, and G. Miao, "Developmental and growth temperature regulation of two different microsomal $\omega-6$ desaturase genes in soybeans," Plant Physiology, vol. 110, no. 1, pp. 311-319, 1996.

[14] J. D. Lee, M. Woolard, D. A. Sleper et al., "Environmental effects on oleic acid in soybean seed oil of plant introductions with elevated oleic concentration," Crop Science, vol. 49, no. 5, pp. 1762-1768, 2009.

[15] M. L. Oliva, J. G. Shannon, D. A. Sleper et al., "Stability of fatty acid profile in soybean genotypes with modified seed oil composition," Crop Science, vol. 46, no. 5, pp. 2069-2075, 2006.

[16] J. L. Alt, W. R. Fehr, G. A. Welke, and D. Sandhu, "Phenotypic and molecular analysis of oleate content in the mutant soybean line M23," Crop Science, vol. 45, no. 5, pp. 1997-2000, 2005.

[17] J. Zhang, J. Zhu, Q. Zhu, H. Liu, X. Gao, and H. Zhang, "Fatty acid desaturase-6 (Fad6) is required for salt tolerance in Arabidopsis thaliana," Biochemical and Biophysical Research Communications, vol. 390, no. 3, pp. 469-474, 2009.

[18] D. Sandhu, J. L. Alt, C. W. Scherder, W. R. Fehr, and M. K. Bhattacharyya, "Enhanced oleic acid content in the soybean mutant M23 is associated with the deletion in the Fad2-la gene encoding a fatty acid desaturase," JAOCS, Journal of the American Oil Chemists' Society, vol. 84, no. 3, pp. 229-235, 2007.

[19] J. D. Lee, K. D. Bilyeu, and J. G. Shannon, "Genetics and breeding for modified fatty acid profile in soybean seed oil," Journal of Crop Science and Biotechnology, vol. 10, no. 3, pp. 201-210, 2007.

[20] T. Buhr, S. Sato, F. Ebrahim et al., "Ribozyme termination of RNA transcripts down-regulate seed fatty acid genes in transgenic soybean," Plant Journal, vol. 30, no. 2, pp. 155-163, 2002.

[21] A. M. Murad, G. R. Vianna, A. M. Machado et al., "Mass spectrometry characterisation of fatty acids from metabolically engineered soybean seeds," Analytical and Bioanalytical Chemistry, vol. 406, no. 12, pp. 2873-2883, 2014.

[22] R. F. Wilson, "The role of genomics and biotechnology in achieving global food security for high-oleic vegetable oil," Journal of Oleo Science, vol. 61, no. 7, pp. 357-367, 2012.
[23] A. T. Pham, J. D. Lee, J. G. Shannon, and K. D. Bilyeu, "Mutant alleles of FAD2-1A and FAD2-1B combine to produce soybeans with the high oleic acid seed oil trait," BMC Plant Biology, vol. 19, p. 195, 2010.

[24] M. M. Paz, H. Shou, Z. Guo, Z. Zhang, A. K. Banerjee, and K. Wang, "Assessment of conditions affecting Agrobacteriummediated soybean transformation using the cotyledonary node explant," Euphytica, vol. 136, no. 2, pp. 167-179, 2004.

[25] Y. Imoto, T. Yamada, K. Kitamura, and A. Kanazawa, "Spatial and temporal control of transcription of the soybean $\beta$-conglycinin $\alpha$ subunit gene is conferred by its proximal promoter region and accounts for the unequal distribution of the protein during embryogenesis," Genes \& Genetic Systems, vol. 83, no. 6, pp. 469-476, 2008.

[26] L. Ma, L. Zhou, Z. J. Hua, G. X. Tang, Z. C. Shen, and H. X. Shou, "Establishment of methods to rapidly and precisely identify transgenic rice and soybean containing herbicide-resistant gene bar and EPSPS," Journal of Zhejiang University, vol. 38, no. 6, pp. 647-654, 2012.

[27] K. Edwards, C. Johnstone, and C. Thompson, "A simple and rapid method for the preparation of plant genomic DNA for PCR analysis," Nucleic Acids Research, vol. 19, no. 6, p. 1349, 1991.

[28] Z. L. Chen, M. A. Schuler, and R. N. Beachy, "Functional analysis of regulatory elements in a plant embryo-specific gene," Proceedings of the National Academy of Sciences of the United States of America, vol. 83, no. 22, pp. 8560-8564, 1989.

[29] T. Fujiwara and R. N. Beachy, “Tissue-specific and temporal regulation of a beta-conglycinin gene: roles of the RY repeat and other cis-acting elements," Plant Molecular Biology, vol. 24, no. 2, pp. 261-272, 1994.

[30] Y. Zhao, Q. Qian, H. Wang, and D. Huang, "Hereditary behavior of bar gene cassette is complex in rice mediated by particle bombardment," Journal of Genetics and Genomics, vol. 34, no. 9, pp. 824-835, 2007. 

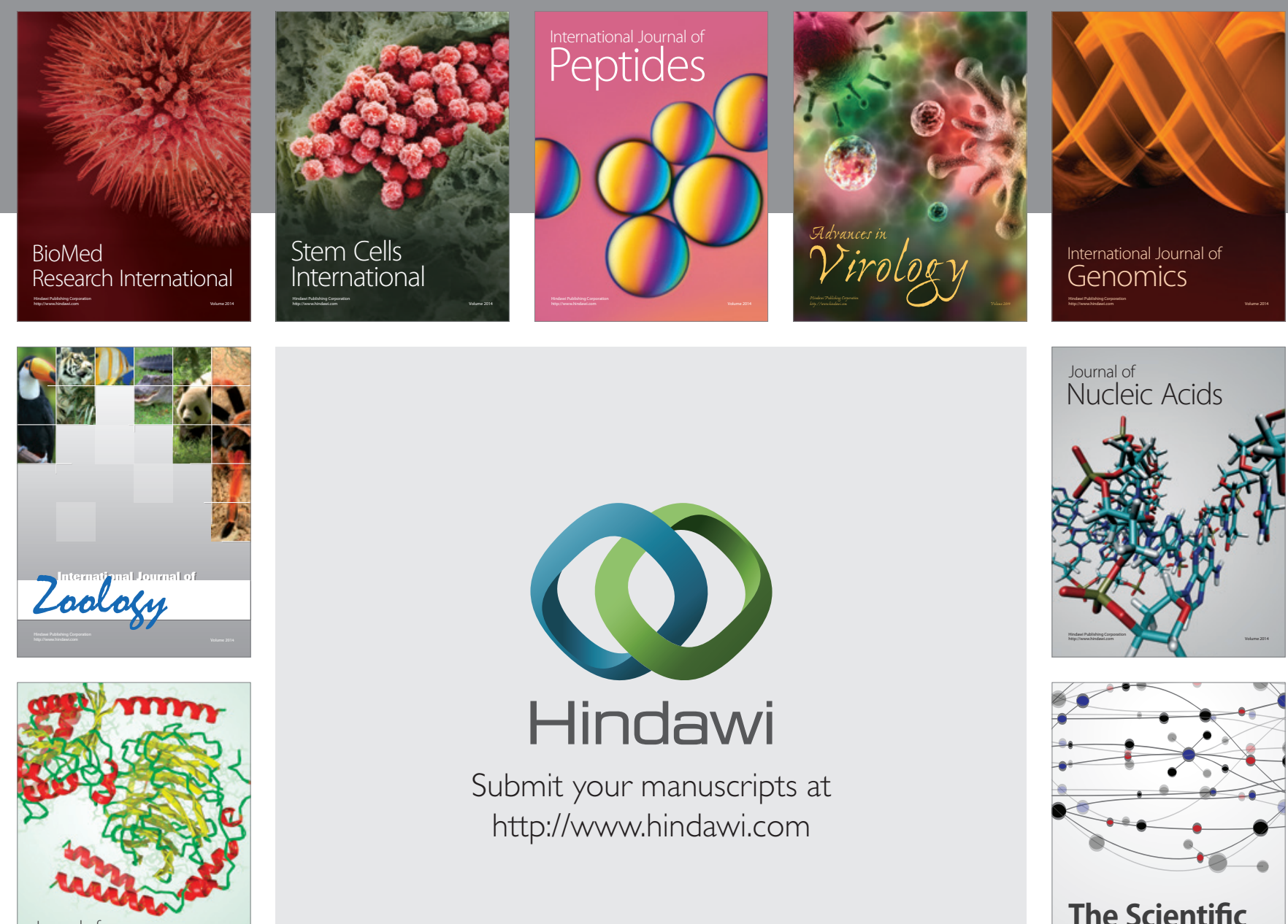

Submit your manuscripts at

http://www.hindawi.com

Journal of
Signal Transduction
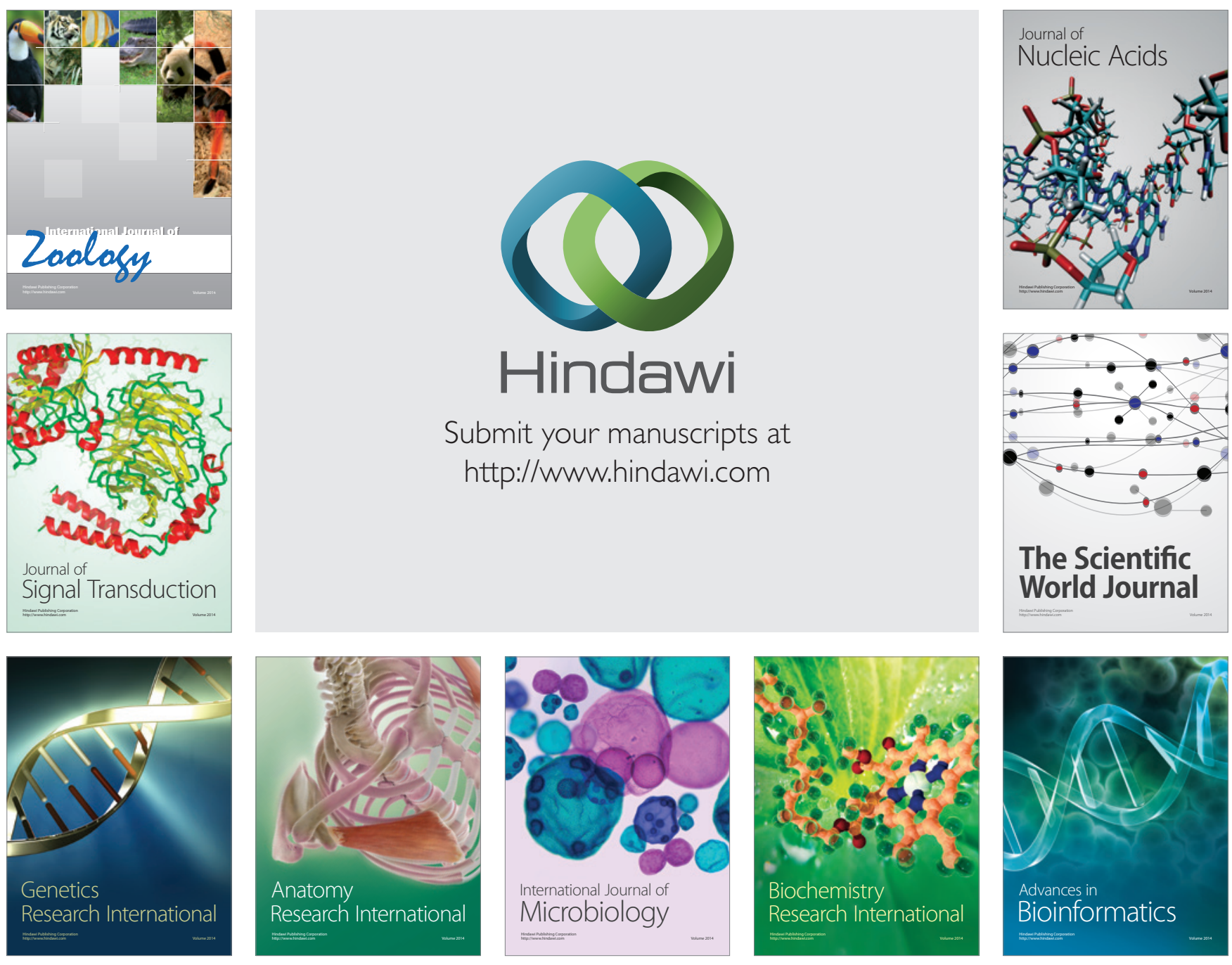

The Scientific World Journal
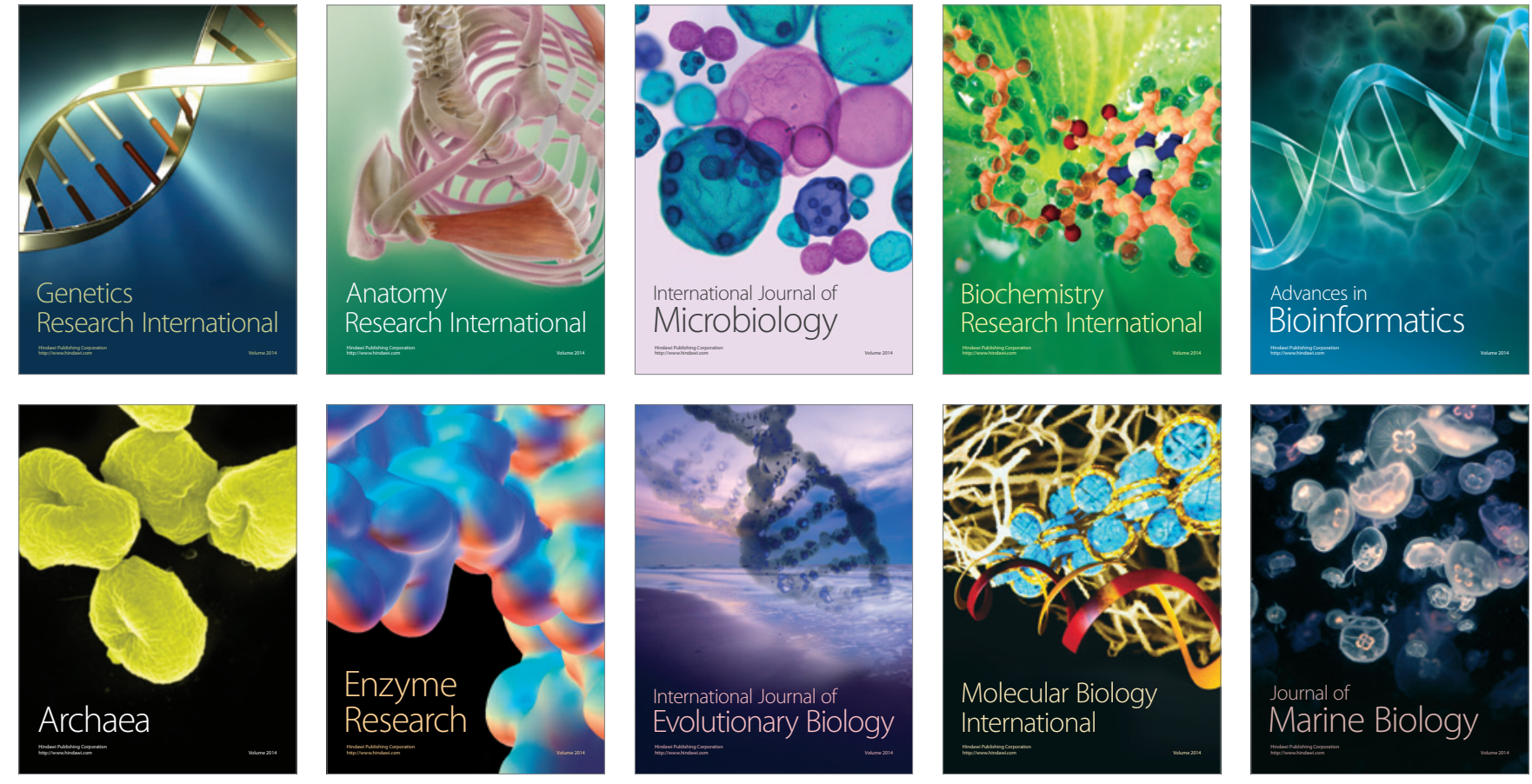